\title{
Comparison of the Effect of Neurofeedback with Neurofeedback Plus Barkly's Parental Training on Auditory Attention Dimensions and Comprehension among Children with Attention Deficit Hyperactivity Disorder
}

\author{
Elaheh Hajehforoush $^{1}$, Elham Foroozandeh",*, Hamid Mirhosseini ${ }^{3}$, Ahmad Abedi ${ }^{4}$ \\ ${ }^{1}$ PhD Student in Psychology, School of Educational Sciences and Psychology, Isfahan (Khorasgan) Branch, Islamic Azad \\ University, Isfahan, Iran \\ ${ }^{2}$ Assistant Professor, Department of Psychology, School of Psychology, Naein Branch, Islamic Azad University, Naein, Iran \\ ${ }^{3}$ Assistant Professor, Research Center for Addiction and Behavioral Sciences, Yazd Shahid Sadoughi University of Medical \\ Sciences, Yazd, Iran \\ ${ }^{4}$ Associate Professor, Department of Psychology, School of Educational Sciences and Psychology, University of Isfahan, \\ Isfahan, Iran
}

* Corresponding Author: Elham Foroozandeh, Department of Psychology, School of Psychology, Naein Branch, Islamic Azad University, Naein, Iran. Email: elham_for@yahoo.com

Received: 09.07.2018

Accepted: 10.11 .2018

\section{How to Cite this Article:}

Hajehforoush E, Foroozandeh E, Mirhosseini H, Abedi A. Comparison of the Effect of Neurofeedback with Neurofeedback Plus Barkly's Parental Training on Auditory Attention Dimensions and Comprehension among Children with Attention Deficit Hyperactivity Disorder. Avicenna J Clin Med. 2018; 25(3): 142-150. DOI: 10.21859/ajcm.25.3.142

\section{Abstract}

Background and Objective: Attention deficit/hyperactivity disorder (ADHD) is one of the most common psychiatric disorders that causes educational, social, and family problems. The main aim of present study was to compare the efficacy of of neurofeedback and neurofeedback plus Barkly's parental training on auditory attention dimensions and comprehension among ADHD Children.

Materials and Methods: This research was a clinical trial study with two experiment and one sham control groups in three stages of pre-test, post-test, and ten weeks follow-up test. A total number of 42 elementary ADHD boys along with their mothers were selected using purposive sampling technique in 2017. The partcipants were assigned to two experimental and one control groups randomly. Those in the experimental group received neurofeedback training in 30 sessions (i.e., 30-min sessions 3 days a week). Parents of the compound group received nine sessions of training based on Barkley's model for an hour. Students in the control group had neurofeedback only with random rewards without any definite setting. All the participants were assessed in three stages by Integrated Visual and Auditory Continues Performance Test. Data were analyzed using SPSS software (version 23) through repeated measure ANOVA.

Results: The obtained results of post-test and follow-up revealled a significant increase in auditory vigilance $(\mathrm{P} \leq 0.005)$, focus $(\mathrm{P} \leq 0.001)$, speed $(\mathrm{P} \leq 0.012)$, and auditory comprehension $(\mathrm{P} \leq 0.003)$, as well as a significant decrease in ADHD symptoms, compared to the results of the control group. However, the difference between the two experimental groups was not significant.

Conclusion: Neurofeedback training and neurofeed plus Barkly's parental training equally increase auditory attention dimension and comprehension among ADHD children.

Keywords: Attention Deficit Disorder with Hyperactivity, Auditory Attention, Barkley’s Parental Training, Neurofeedback 


\title{
مقايسه تأثير نوروفيدبك و نوروفيدبك به همراه آموزش والدكرى باركلى بر ابعاد

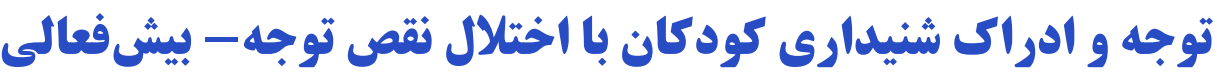

\author{
الهه حجدفروش'، الهام فروزنده r.*; حميد ميرحسينى"، احمد عابدى \\ ' دانشجوى دوره دكترى روانشناسى، دانشكده علوم تربيتى و روانشناسى، واحد اصفهان (خوراسگان)، دانشگاه آزاد اسلامى، اصفهان، ايران

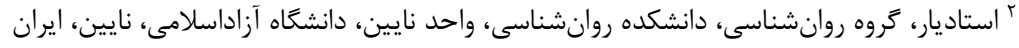

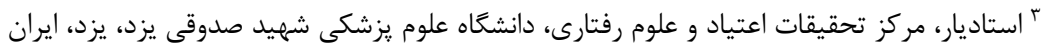

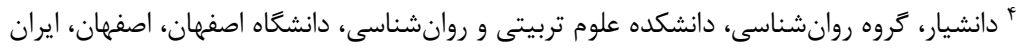 \\ * *ويسنده مسئول: الهام فروزنده، گروه روانشناسى، دانشكده روانشناسى، واحد نايين، دانشگاه آزاداسلامى، نايين، ايران. \\ ايميل:elham_for@yahoo.com
}

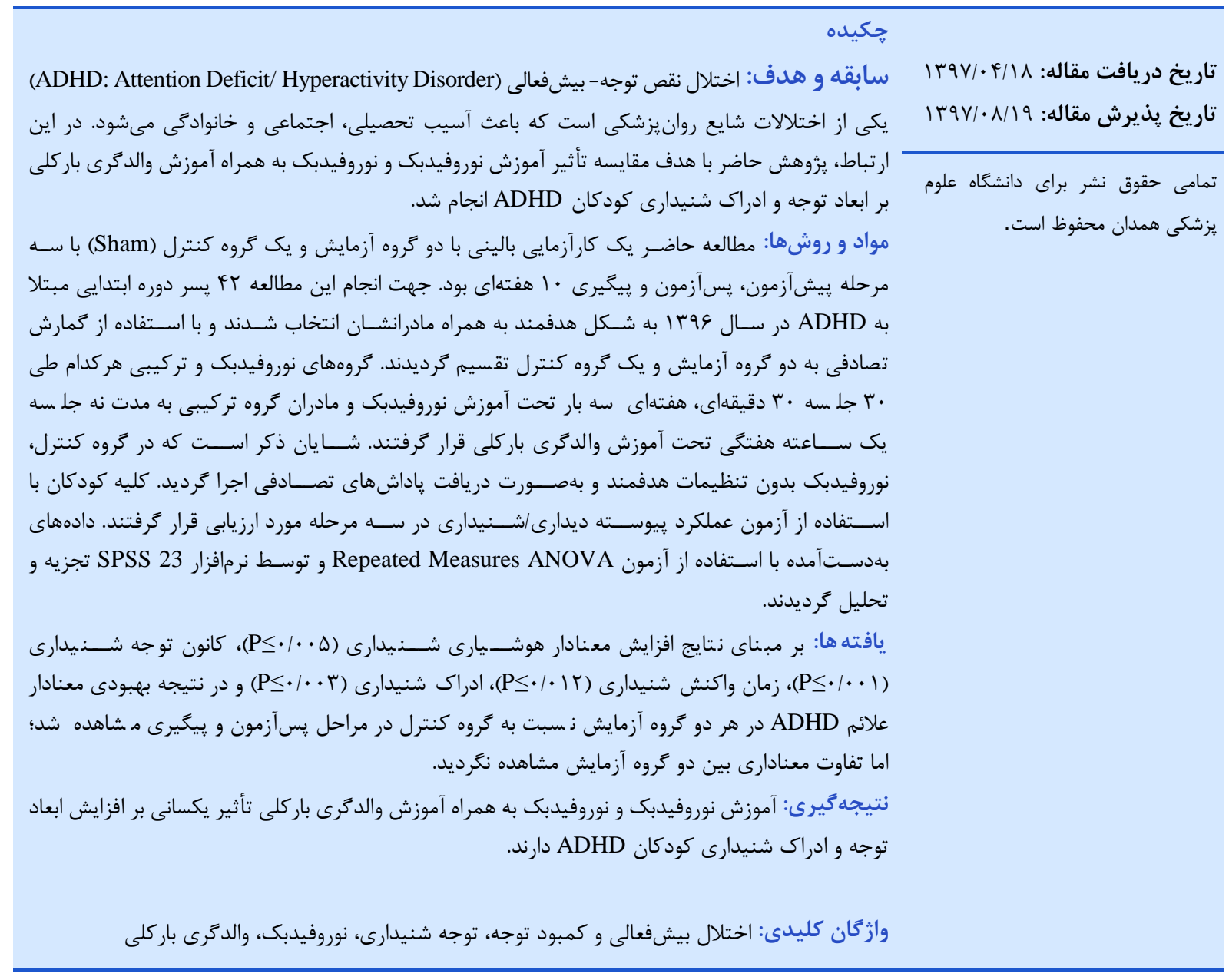

مقلدمه

عمدتاً بىتوجه، بيشفعال/تكانشگر و مركب مىباشد كه نوع

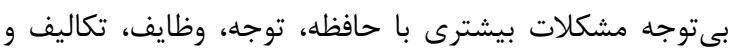

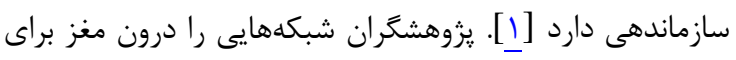

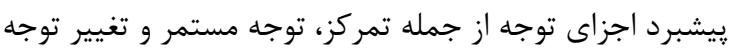
مطرح كردهاند. آنها معتقد هستند كه مناطق آهيانهاى بيرونى و
يكى از اختلالات دوران كودكى، اختلال نقص توجه/بيش

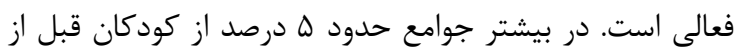

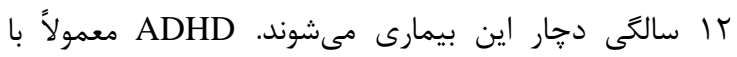
عوارضى مانند كاهش توانايىهاى اجرايى در مدرسه، يِيشرفت

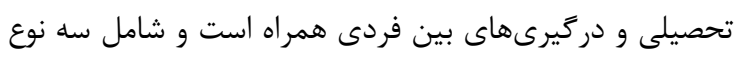


براساس برخى از مطالعات مىتواند جايكزينى براى دارودرمانى

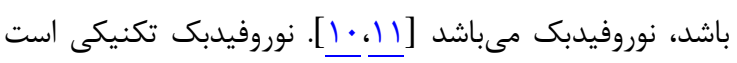

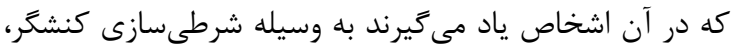

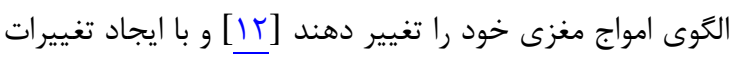

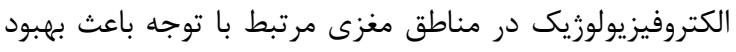

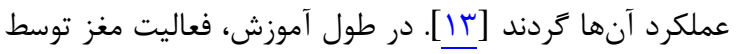

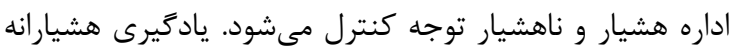

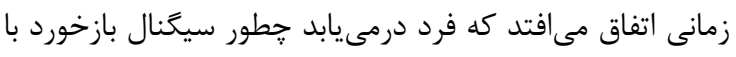

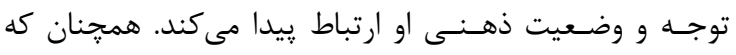

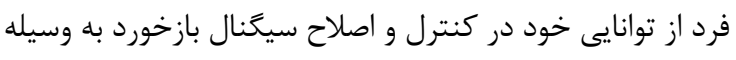

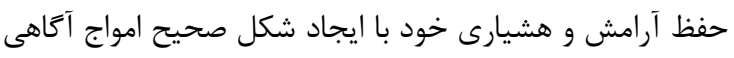

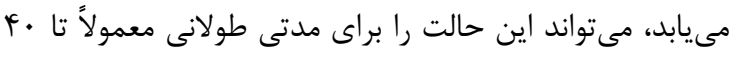

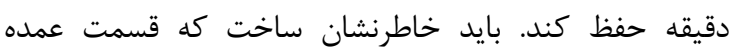

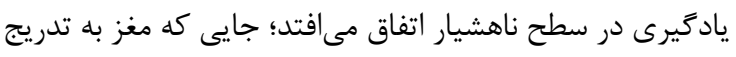

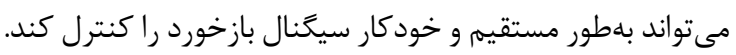

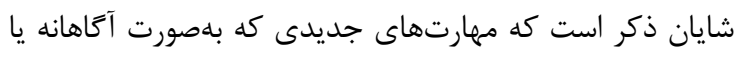

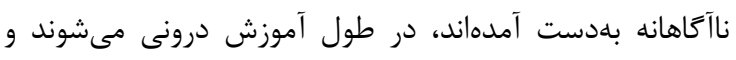

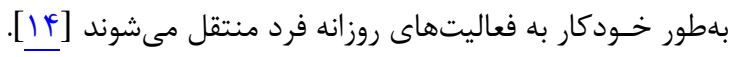

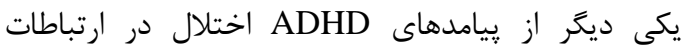

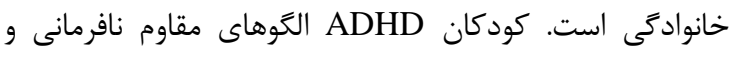

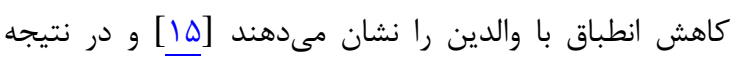

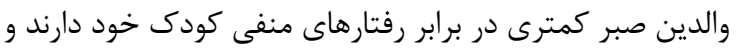

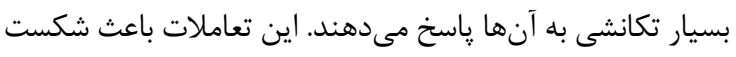

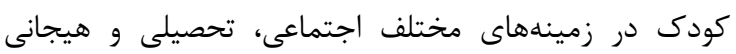
مىشود [19] يكى از روشهاى فرزنديرورى كه به كاهش واكنشيذيرى

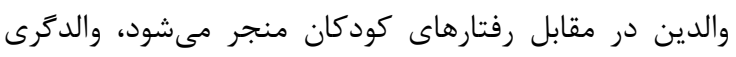

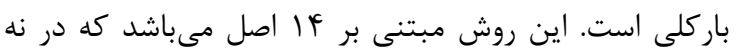

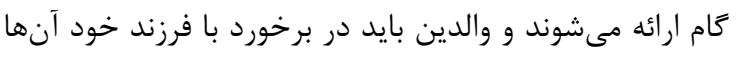

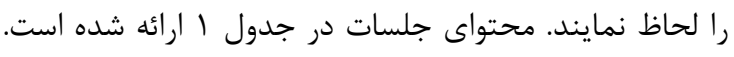

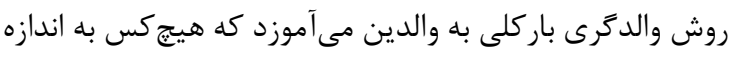

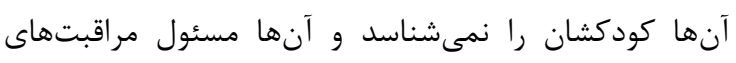
تحصيلى و تخصصى از كودى خود هستند. همجنينين، به آنها آنها

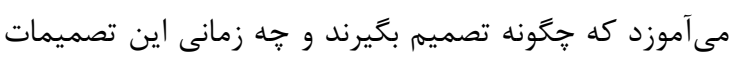
را اتخاذ نمايند [IV] كودكان ADHD در ابعاد توجه شنيدارى از جمله هوشيارى،

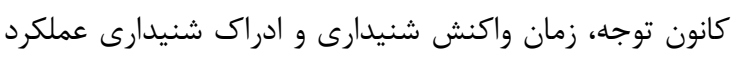

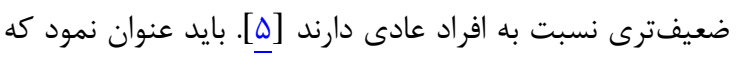

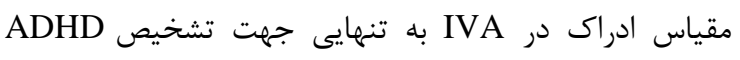

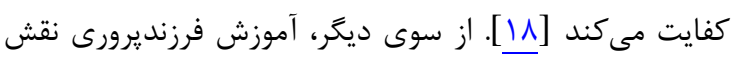

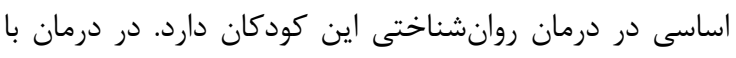

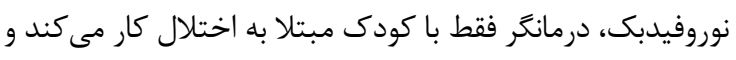

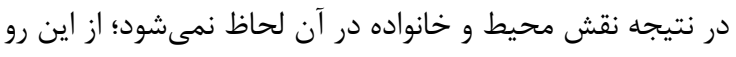

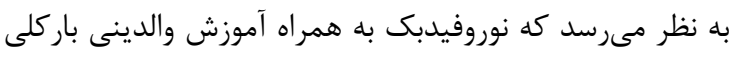

جسم مخطط با كاركردهاى اجرايى/حركتى و هييوكامٍ با باني

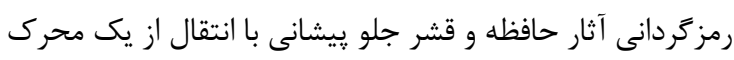

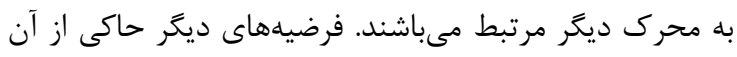

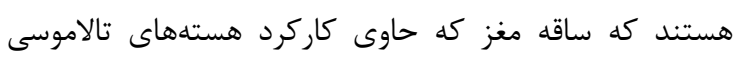

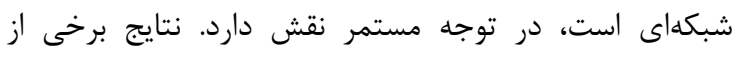

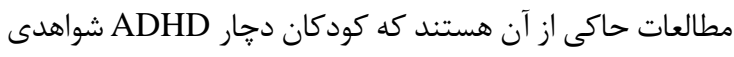

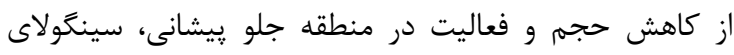

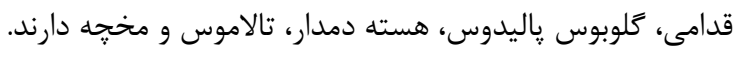

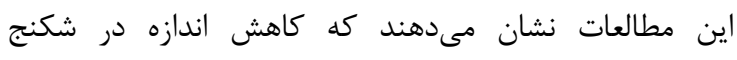

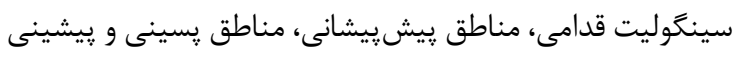

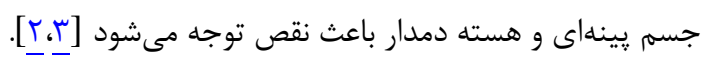

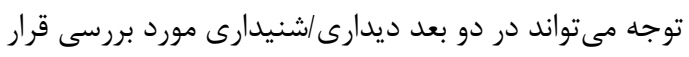

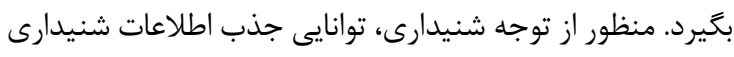

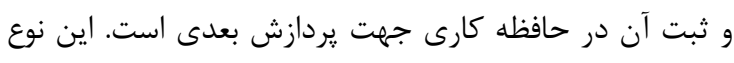

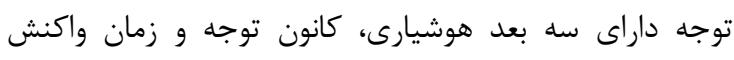

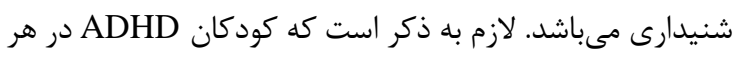

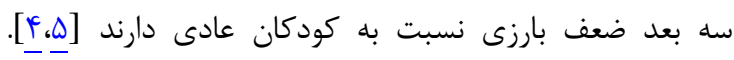

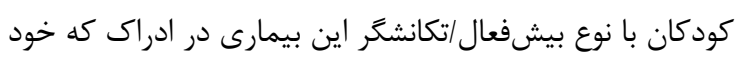

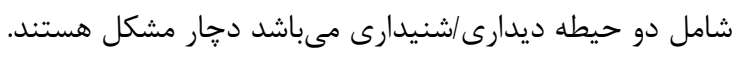

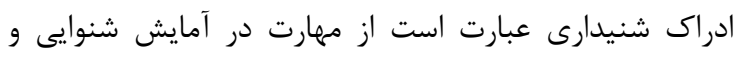

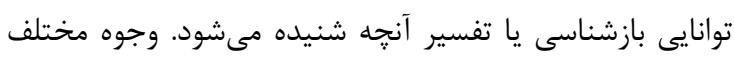

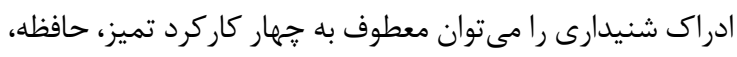

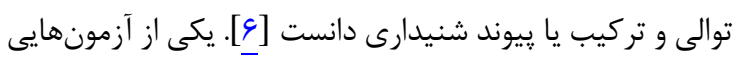

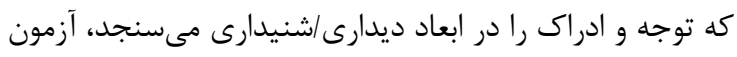

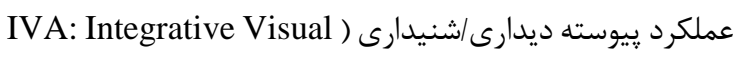
هوشياري (and Auditory Performance Test هوشيارى شنيدارى آزمون IVA عدم توجه شنيدارى به وسيله

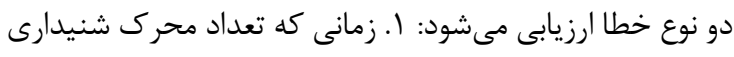

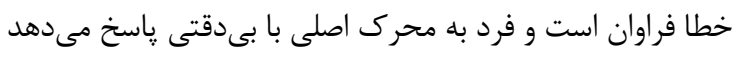

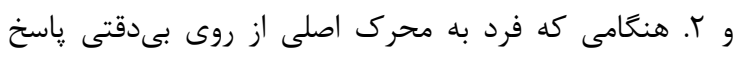

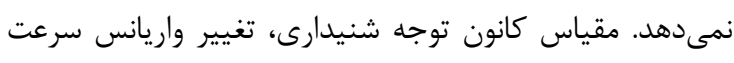

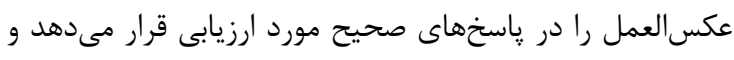

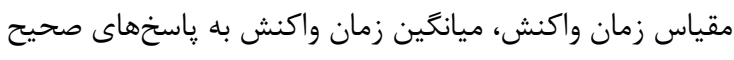

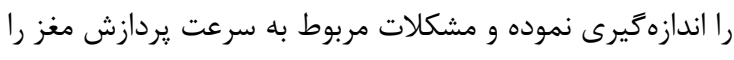

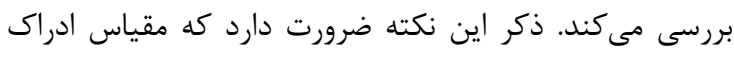

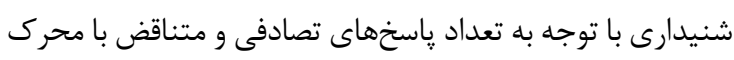

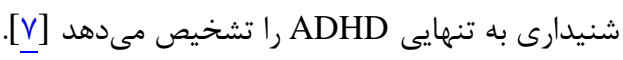

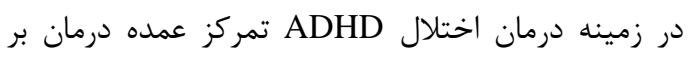

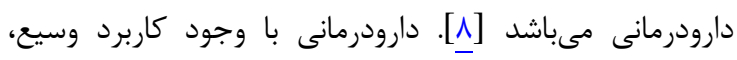

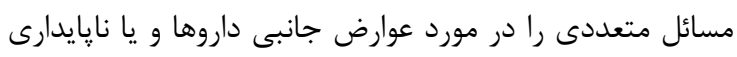

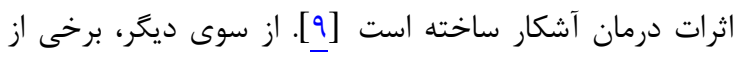

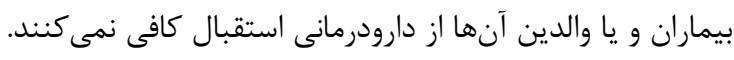

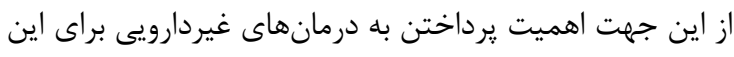

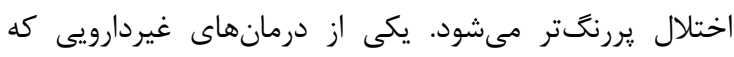




\begin{tabular}{|c|c|}
\hline محتوا & 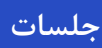 \\
\hline معرفى ADHD؛ آموزش بازخورد فورى به عملكرد كودكان؛ تشويق بيشتر و ايجاد انخيزش بيرونى جهت يِيروى از قواعد & اول \\
\hline آموزش ايجاد ثبات در عملكرد؛ برنامهريزى براى آينده؛ تمرين بخشش & 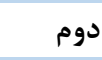 \\
\hline آموزش مديريت زمان؛ آكاهى از نوع رابطه والد/فرزندى & 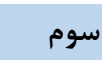 \\
\hline افزايش توجه مثبت به كودى از طريق بازى و بهبود يذيرش او از طريق بهبود نحوه نظارت و سريرستى والدين بر كار كودى & جهارم \\
\hline 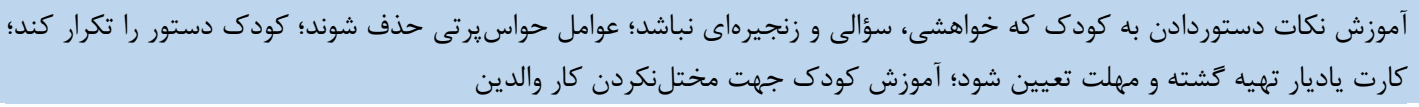 & 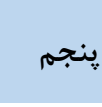 \\
\hline ايجاد يك سيستم زتون خانكَى؛ جَّونكَى اجراى آن؛ آموزش برنامه كسب امتياز خانكى & ششم \\
\hline تنبيه رفتار نادرست به شيوهاى سازنده (آشنايى با دستورالعمل جريمه كودى و وقفه تربيتى) & 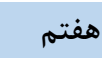 \\
\hline مديريت كودى در مكانهاى عمومى از طريق تعيين قواعد، مشوقها و تنبيهها قبل از ورود به محل و درنظركرفتن فعاليتى براى كودى & هشته \\
\hline 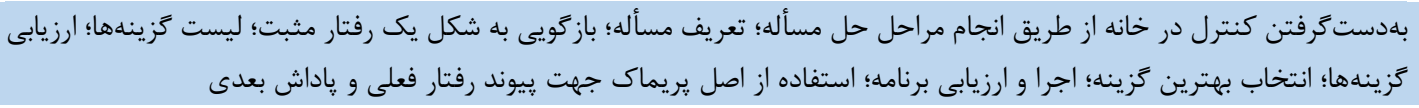 & نهم \\
\hline سهيمكردن ديكران در تجربيات از نه جلسه كَذشته & ييخيرى \\
\hline
\end{tabular}

مطالعه در نظر گرفته شدند. با توجه به اينكه مطالعه در تابستان

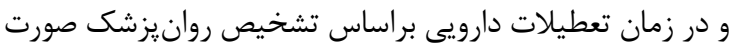

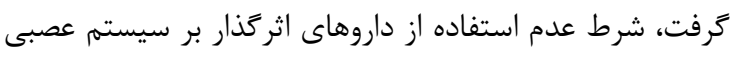

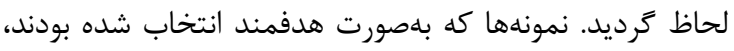

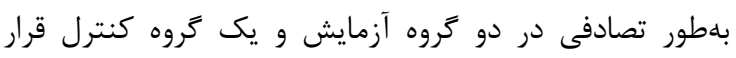

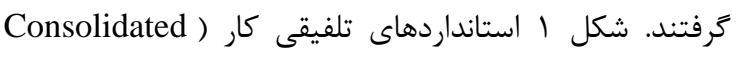
Standards of Reporting Trials شركت كنندگان در مطالعه را نشان مى دهد.

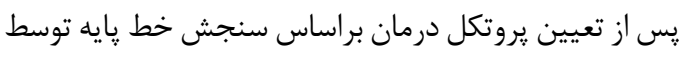

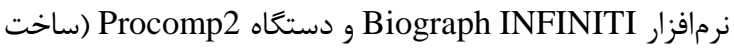
شركت Thought Technology كانادا) براساس نتايج خط پِايه

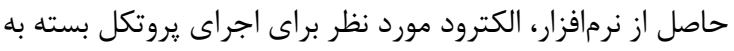

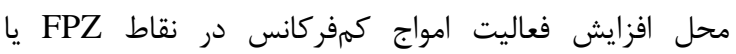

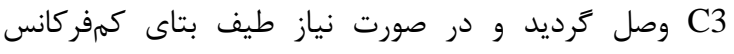
(TMR: Sensory Motor Response)

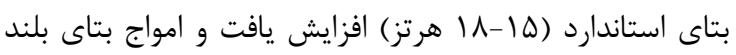
كاهش داده شد و كودكان تروه نوروفيدبك طى (High Beta)

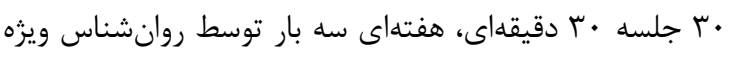

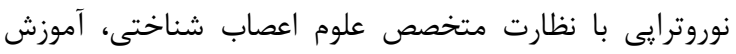

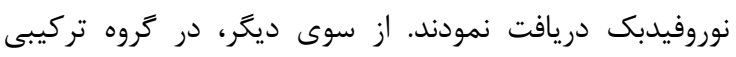

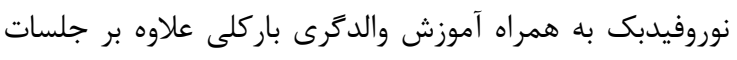

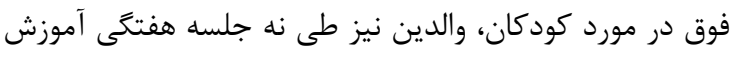

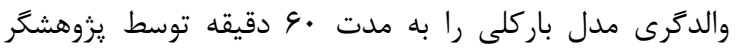

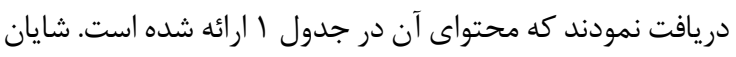

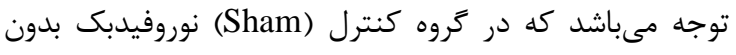

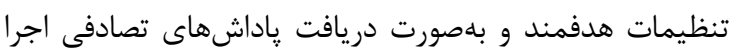

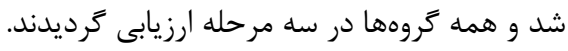

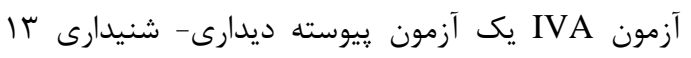

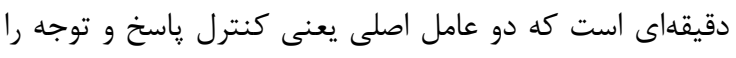
مورد ارزيابى قرار مىدهد. اين آزمون بر مبناى روائي راهنماى
به علت دركيركردن كودكان مبتلا و خانواده آنها تأثير بيشترى

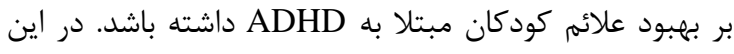

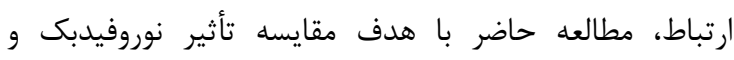
نوروفيدبك به همراه آموزش والدگرى باركلى بر ابعاد توجه و ادراى شنيدارى كودكان داراى نقص توجه/بيشفعالى انجام شد.

مواد و روش ها

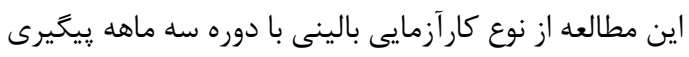
بود كه توسط كميته اخلاق دانشعاه آزاد اسلامى واحد اصفهان

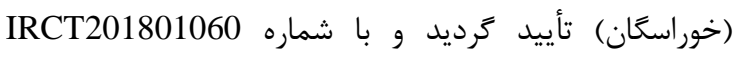

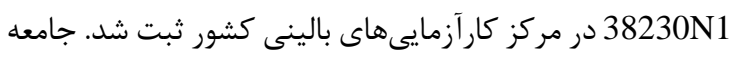

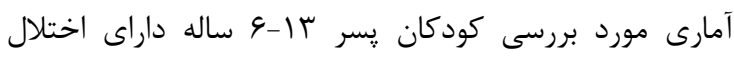
ADHD

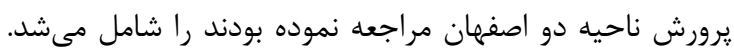

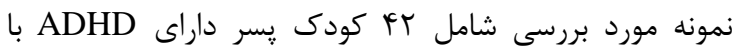

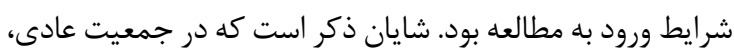
ADHD

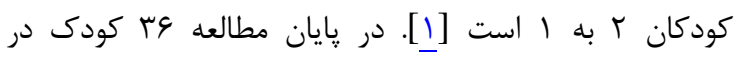

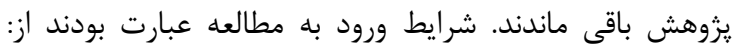

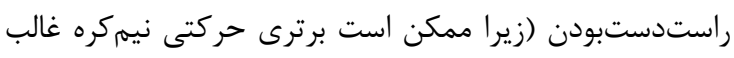

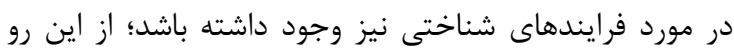

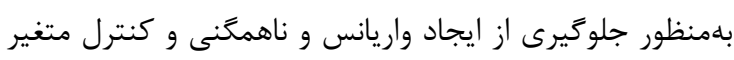

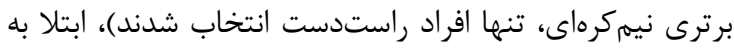

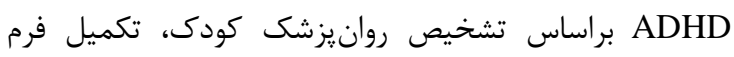

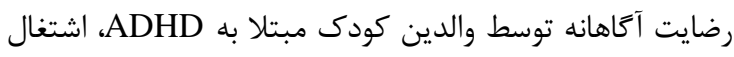
به تحصيل در پايههاى اول تا ششم دبستان بدون سابقه تكرار

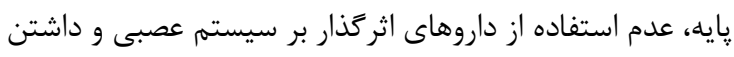
بهره هوشى بالاتر از هـ حاصل از اجراى آزمون هوش وكسلر.

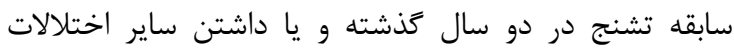

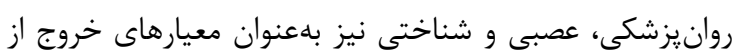




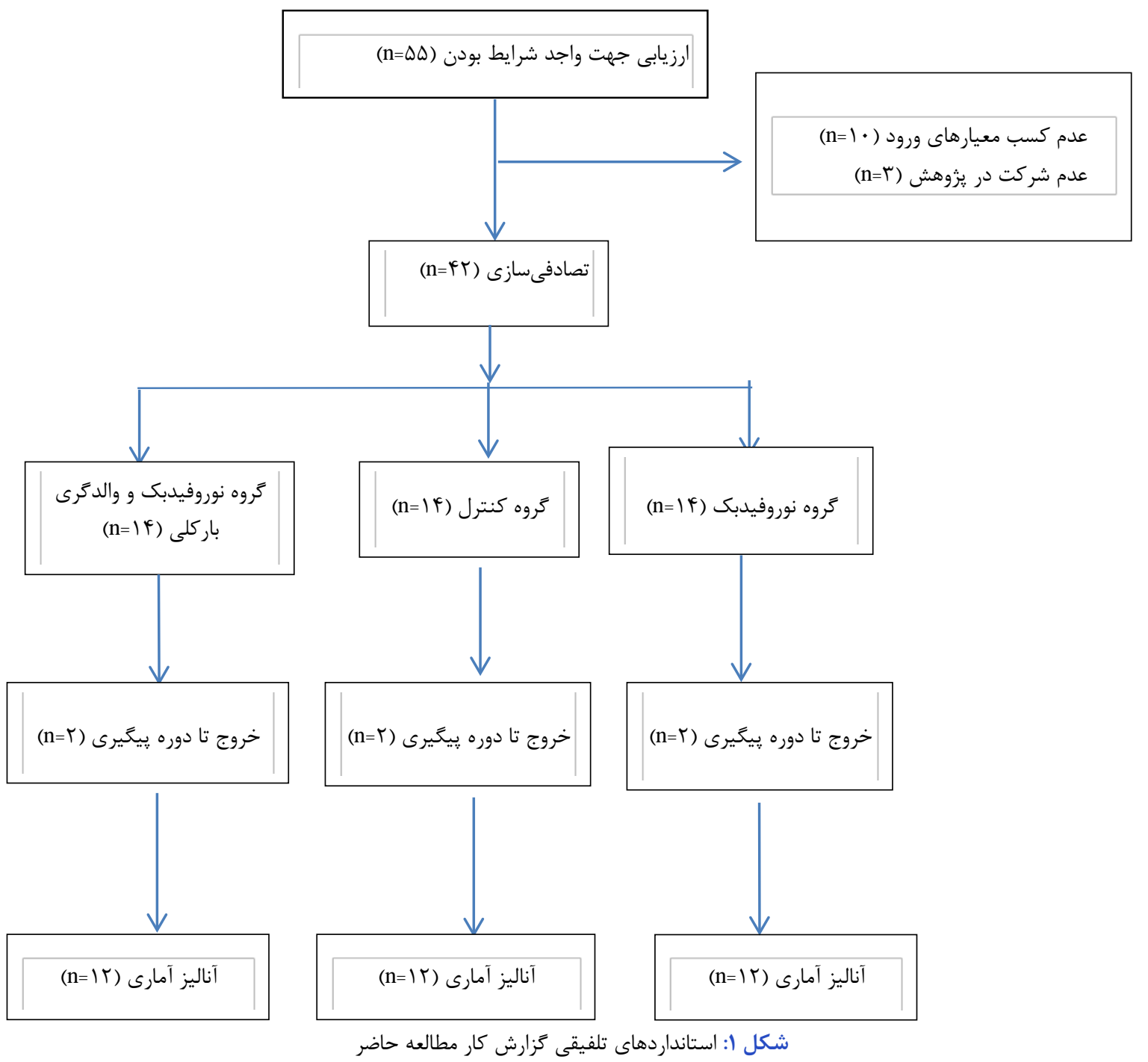

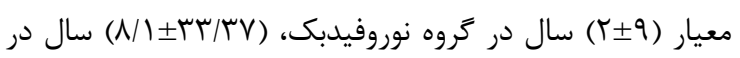

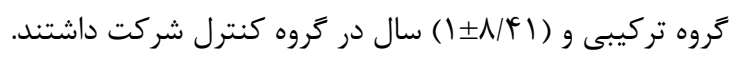

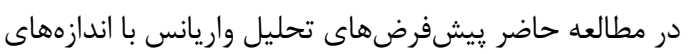

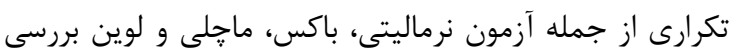

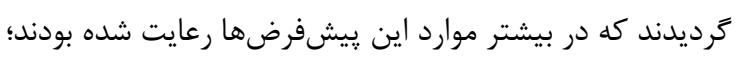

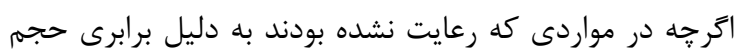

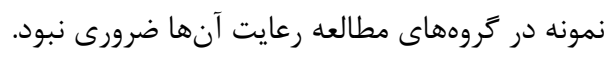

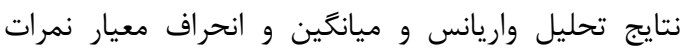

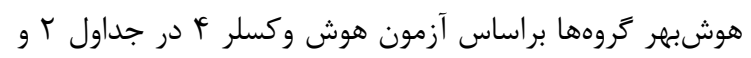

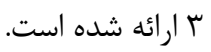

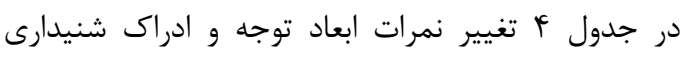

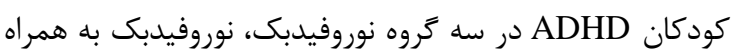

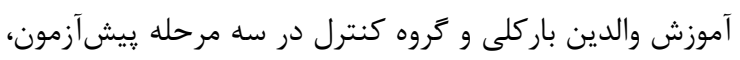

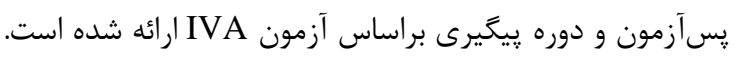

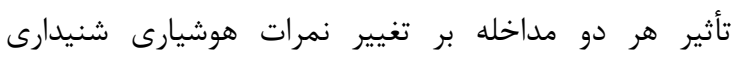

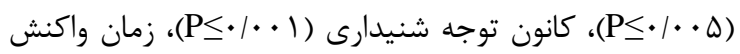

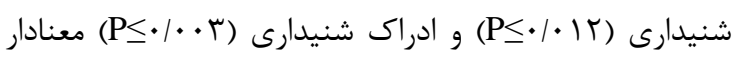

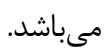
براساس نتايج جدول ه هر دو مداخله نوروفيدبك و
تشخيصى و آمارى اختلالات روانى Diagnostic and) DSM-IV تشو (Sistica Statistical Manual of Mental Disorders نتايج مطالعات كوياى آن هستند كه آزمون IVA از از حساسيت

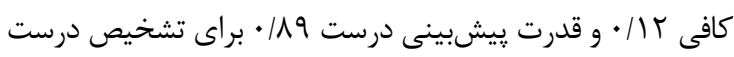
ADHD

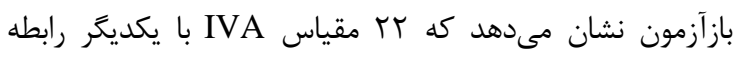

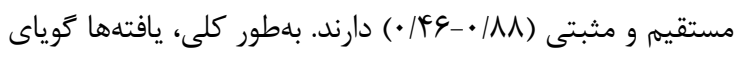

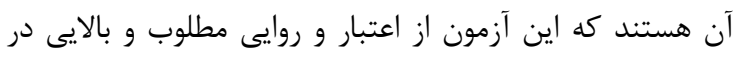

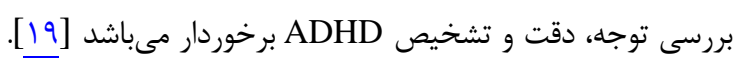

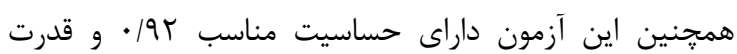

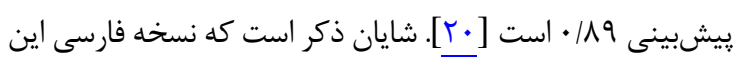

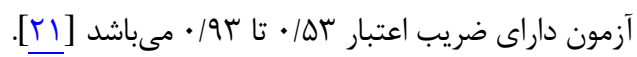

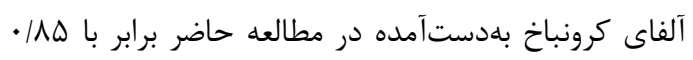

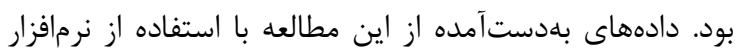
SPSS 23 تحليل كرديدند.

يافته ها

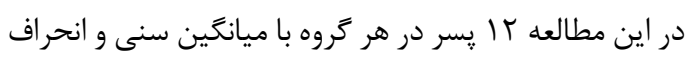


جدول r: ميانكين و انحراف معيار نمرات هوشبهر آزمودنىها براساس آزمون هوش وكسلر

\begin{tabular}{|c|c|c|c|c|c|c|c|c|}
\hline آز توان & اثدازه & سطنادارى & $\mathbf{F}$ & مجانكَور & آزادى & مجذوروات & منبع & متغير \\
\hline$\cdot / \cdot V$ & $.1 \cdot 11$ & - /Arq & . /IVG & $F / T G \mid$ & r & N/VTY & كروه & \multirow{2}{*}{ هوشبهر } \\
\hline- & - & - & - & $T F / V T$ & זr & $1 / 9 / 19$ & خطا & \\
\hline
\end{tabular}

جدول ب: نتايج تحليل واريانس يكراهه جهت بررسى تفاوت ميانكين متغير هوشبهر در گروههاى آزمايش و كنترل

\begin{tabular}{|c|c|c|c|}
\hline انحراف معيار & ميانگين & 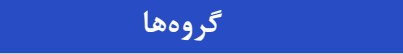 & متغير \\
\hline F/VF & $9 \Delta / \wedge r$ & نوروفيدبك & \multirow{3}{*}{ هوش بهر } \\
\hline$\Delta / q^{\prime}$ & $৭ \Delta / \vee \Delta$ & نوروفيدبك و آموزش والدگرى باركلى & \\
\hline$F / \wedge \varepsilon$ & $q F / V D$ & 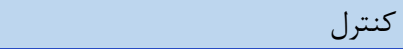 & \\
\hline
\end{tabular}

$\mathrm{P} \leq \cdot / \cdot \Delta$

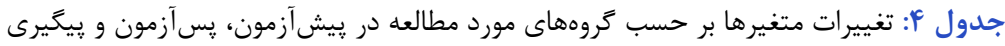

\begin{tabular}{|c|c|c|c|c|c|c|c|c|c|c|}
\hline \multirow{2}{*}{ معنادارى } & \multicolumn{3}{|c|}{ كروه كنترل (II) } & \multicolumn{3}{|c|}{ كروه نوروفيدبك و آموزش والدينى (rn=1r) } & \multicolumn{3}{|c|}{ كروه نوروفيدبك (n=|r) } & \multirow{2}{*}{ متغيرها } \\
\hline & بيعيرى & يس آزمون & بيش آزمون & بيعيرى & يس آزمون & ييش آزمون & بينيرى & يس آزمون & بيش آزمون & \\
\hline$\% \Delta^{\circ}$ & $11 / \pi \wedge \pm \varepsilon 9 / \pi T$ & $19 / 6 \mid \pm 99 / 9$. & $11 / \wedge \pm V W / T^{\prime}$ & $q / .9 \pm \Lambda \Lambda / \Lambda$. & $N(\Delta \cdot \pm 9 T / \cdot T$ & $11 / \pi T \pm 9 N \cdot \Delta$ & Vi $/$ Y $\pm A N / 9 \Delta$ & $9 / \mathrm{Tr} \pm 9 \% / \cdot 4$ & $V / I T \pm 9 \Delta / T r$ & هوشيارى شنيدارى \\
\hline $1 . .1^{\circ *}$ & $r / \Lambda 9 \pm 9 q / / 4 \uparrow$ & $9 / N \cdot \pm 9 V / 10$. & $9|\Delta| \pm 9 \Delta / \lambda$. & $919 \mathrm{~A} \pm \mathrm{VV/T \Lambda}$ & $V / G T \pm A g / T T$ & $F / \lambda \cdot \pm \Delta \Delta / / 9 V$ & $V_{V} / Y \pm \lambda T / \Lambda \Delta$ & $F(r 9 \pm 90 / f 4$ & $r / r \cdot \pm \Delta / / 4 \cdot$ & كانون توجه شنيدارى \\
\hline$\% 1 r^{\circ}$ & $9 r / / V \pm \lambda \cdot r / \cdot \Lambda$ & ADNY \pm YAN/TT & $\Lambda g / V \cdot \pm V A V / T T$ & $|M N T \cdot \pm 99 \%| \cdot 1$ & $F \cdot 19 \Delta \pm V \mid T N \Delta \Delta$ & $\Delta Q / / \Delta \pm V \varphi \wedge / v \Delta$ & GNQY $\pm 9 A V / \Delta T$ & $\Delta N / 9 Y \pm 9 / T / \Delta$. & $\Delta r / \cdot V \pm V Q \Lambda / T \Delta$ & 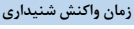 \\
\hline$\% r^{\circ \circ}$ & $\mid r / T+ \pm \lambda / / 1 \Delta$ & $V / \Delta f \pm \lambda / / \uparrow \Lambda$ & $1 \cdot \pi Y \pm \lambda F / 19$ & $9 / r Y \pm 9 / 94$ & $9 / / V \pm 9 \Delta / V \lambda$ & $M / V \pm V \Delta / 9 Y$ & $F \mid 9 \lambda \pm 9 \Delta /+\Lambda$ & $r / \Delta r \pm 9 \Delta / 99$ & $N(\Delta A \pm A G \mid 9 T$ & ادراك شنيدارى \\
\hline
\end{tabular}

${ }^{*} \mathrm{P}<\cdot / \cdot \Delta$

جدول ه: نتايج آزمون تعقيبى شفه جهت متغيرهاى كانون توجه، سرعت يردازش، هوشيارى و ادراك شنيدارى

\begin{tabular}{|c|c|c|c|c|c|}
\hline معنادارى سطح & استاندارد & تفاوت ميانكين & ساير تروهها (J) & كروه هدف (I) & متغير \\
\hline $\begin{array}{l}\cdot / \cdot V f \\
\cdot / \cdot l^{* * *} \\
\cdot / \cdot V^{* * * *}\end{array}$ & $\begin{array}{l}1 / 91 \\
1 / 91 \\
1 / 91\end{array}$ & $\begin{array}{l}\text { r/Ar } \\
\text { Q/TI } \\
\Delta / \uparrow \wedge\end{array}$ & 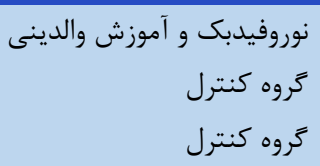 & نوروفيدبك & كانون توجه شنيدارى \\
\hline $\begin{array}{l}\cdot / 9 \Delta 9 \\
\cdot / \cdot Y V^{*} \\
\cdot / \cdot r Y^{*}\end{array}$ & $\begin{array}{l}\text { tN/AT } \\
\text { tN/AT } \\
\text { tN/AT }\end{array}$ & $\begin{array}{l}19 / 19 \\
-\Delta N / 19 \\
-V V / r \Lambda\end{array}$ & 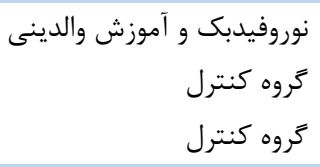 & نوروفيدبك & زمان واكنش شنيدارى \\
\hline $\begin{array}{l}\cdot / 91 \mathrm{~V} \\
\cdot / \cdot r \cdot * \\
\cdot / \cdot 1 \mathrm{r}^{*}\end{array}$ & $\begin{array}{l}r / F Q \\
r / F Q \\
r / F Q\end{array}$ & $\begin{array}{l}-. / D Q \\
1 \cdot / K F \\
1 \cdot / V q\end{array}$ & 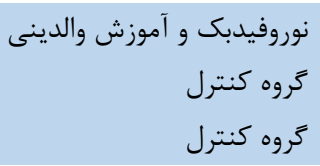 & نوروفيدبك & هوشيارى شنيدارى \\
\hline $\begin{array}{l}\cdot 199 \mathrm{~V} \\
\cdot / \cdot \varphi^{* * * *} \\
\cdot / \cdot r q^{* *}\end{array}$ & 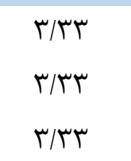 & $\begin{array}{l}T / T / \\
1 \cdot / D T \\
N / T /\end{array}$ & 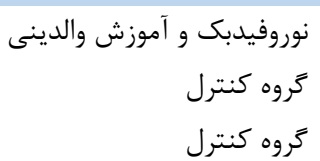 & نوروفيدبك نوفيدبك و آموزش والدينى & ادراى شنيدارى \\
\hline
\end{tabular}

شنيدارى كودكان گروه نوروفيدبك و گروه تركيبى نسبت به گروه

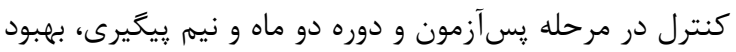

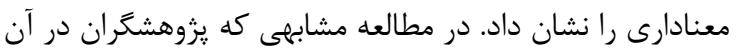

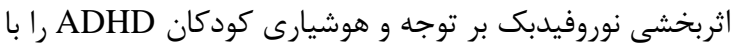

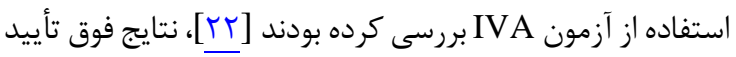

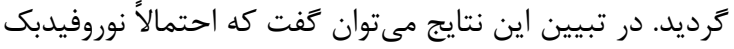

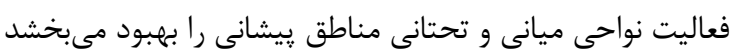

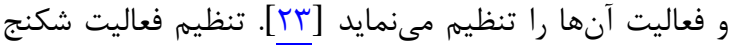

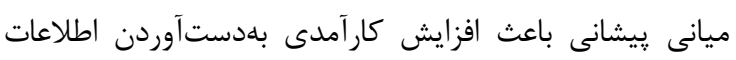

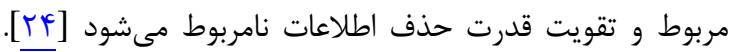

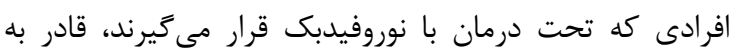

نوروفيدبك به همراه آموزش والدگرى باركلى بر ابعاد توجه و

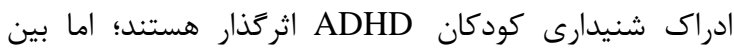

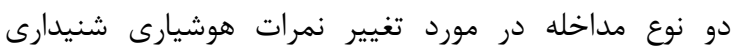
(P $\leq$ •/9AV)

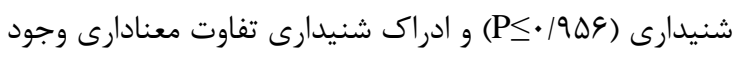
ندارد (PS

در اين مطالعه تأثير درمان نوروفيدبك و نوروفيدبك به همراه

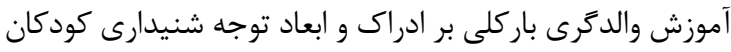

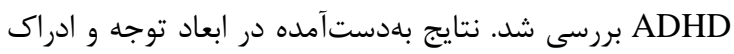


نسبت به اختلال و راهكارهاى اصلاح رفتار به بهبود رابطه والد-

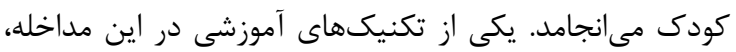

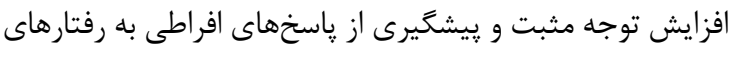

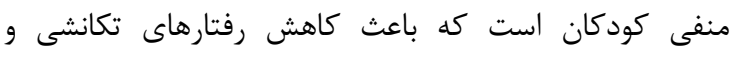

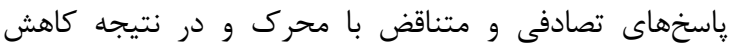

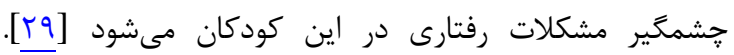

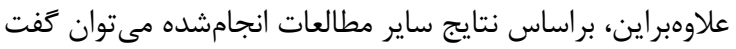

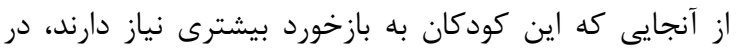

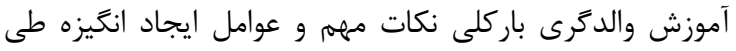

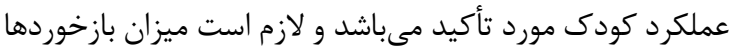
نسبت به رفتارهاى مثبت كودى افزايش يابد؛ در نتيجه احتمالاً اين سبك رفتار موجب كاهش علائم نقص توجه در آنها مى گتردد

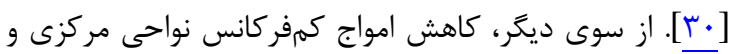

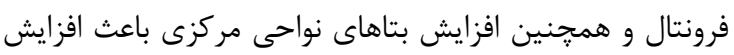

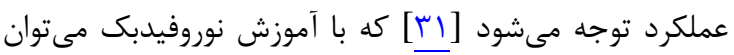

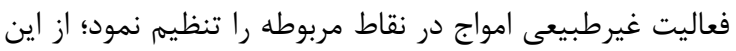

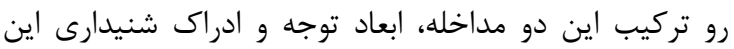

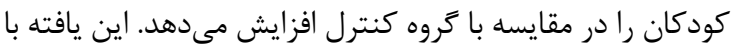

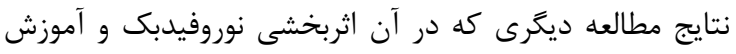

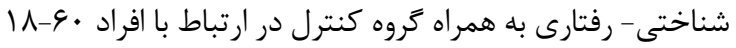

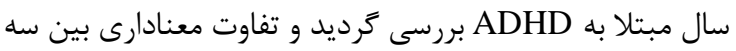

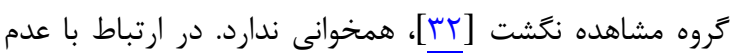

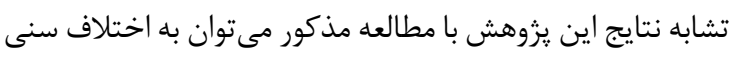

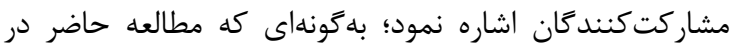

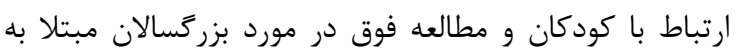
ADHD

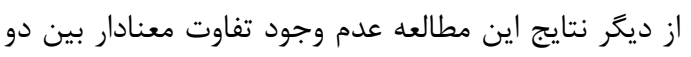
روش نوروفيدبك و روش تركيبى بود. اين يافته با نتايج مطالعات

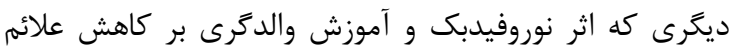

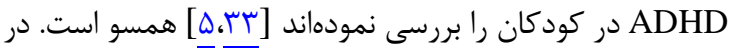

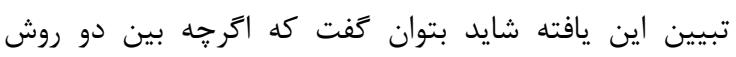

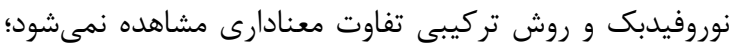

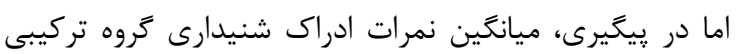

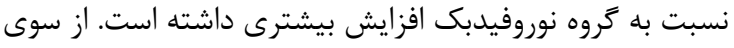

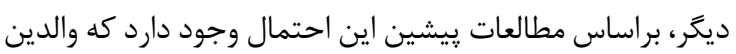

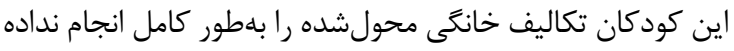

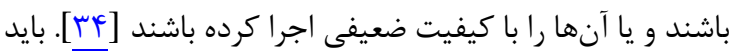

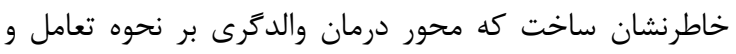

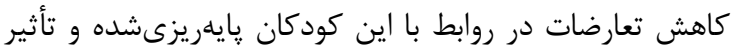

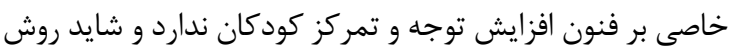

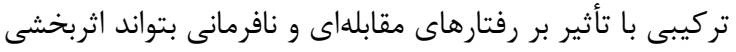

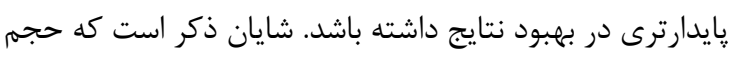

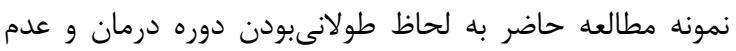

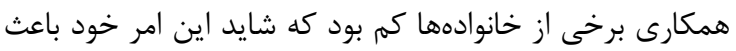

تنظيم فعاليت بخشهاى مورد نظر از مغز خود مىباشند؛ بهعنوان

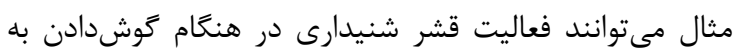

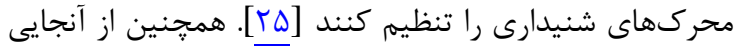

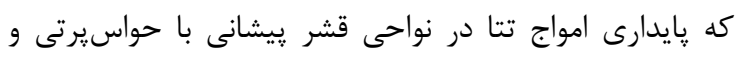

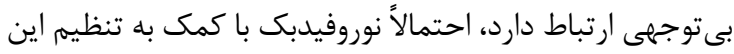

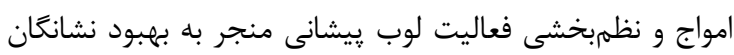

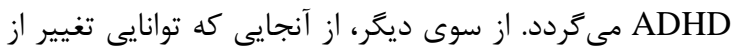

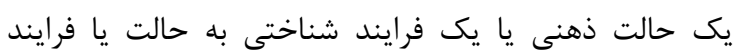
شناختى ديكر بهطور عمده توسط شكنج سينكوليت قدامى اجرا

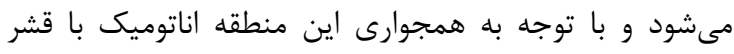

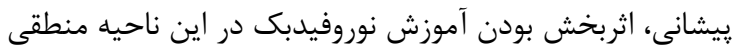
بلنظر مىرسد. براساس شواهد موجود مبنى بر اينكه نسبت امواج

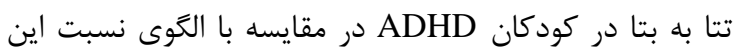

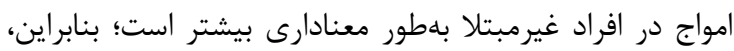

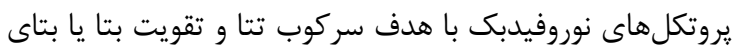

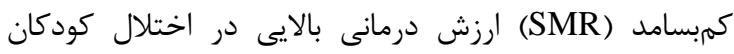

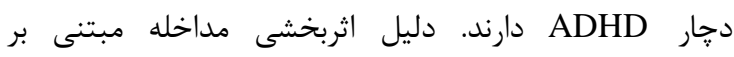

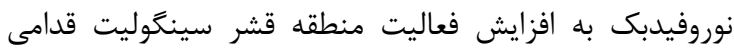

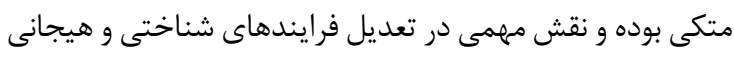

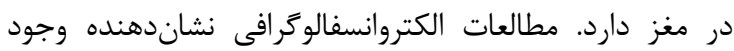
ارتباط منفى بين فعاليت منطقه قشر سينكوليت قدامى و قدرت

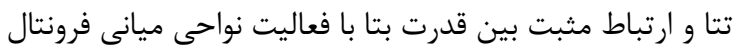

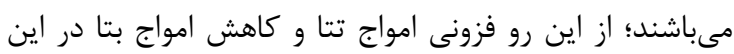

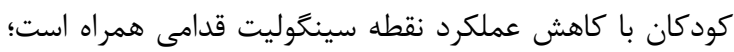

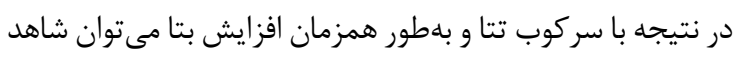

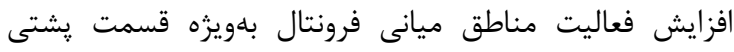

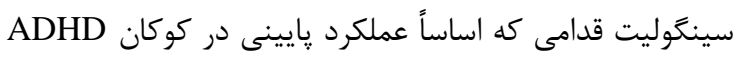

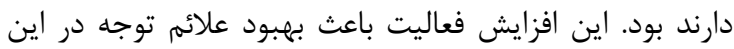

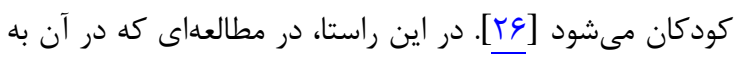

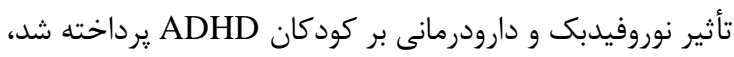

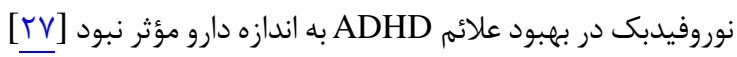

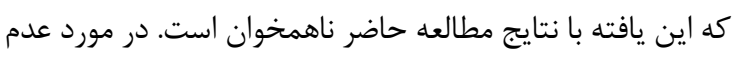

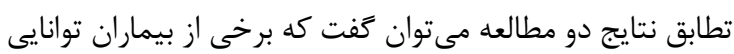

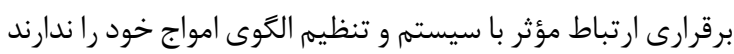

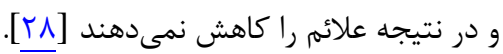

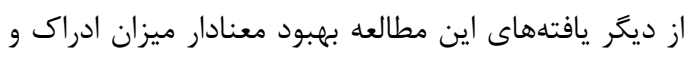

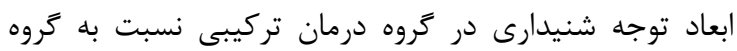

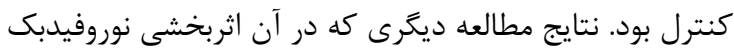

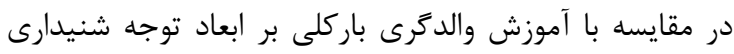

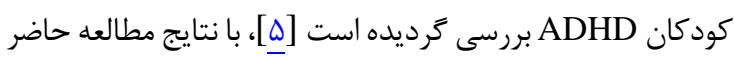

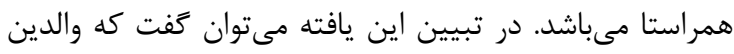

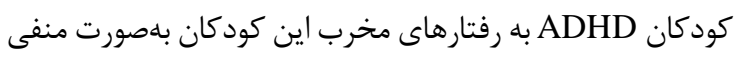
ياسخ مى دهند و موجب افزايش رفتارهاى مقابلهاى اين كودكان

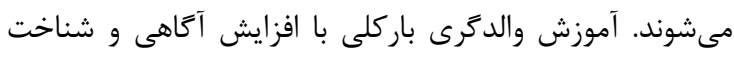


حاضر بين اين دو روش تفاوت معنادارى وجود نداشت؛ از اين رو در مواردى كه هدف پايدارى بيشتر نتايج است، روش تركيبى رونى

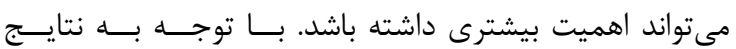

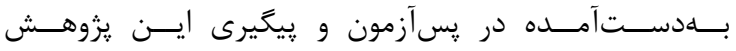

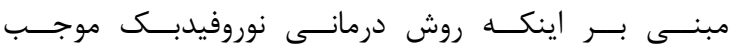

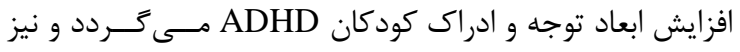

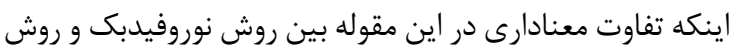

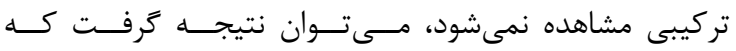

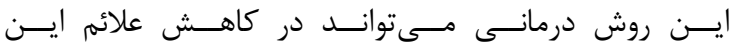

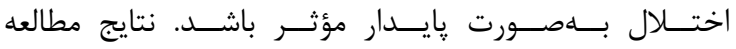

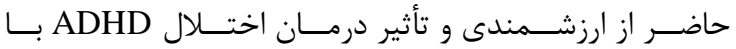

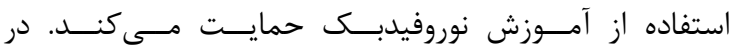

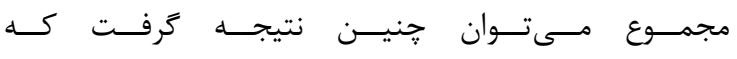

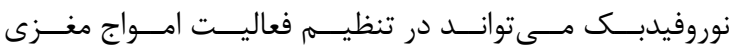

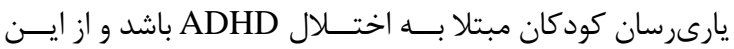

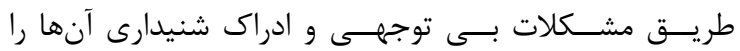

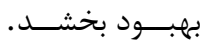

\section{تشكر و قدردانى}

اين مقاله بركرفته از پاياننامه دوره دكترى روانه روانشناسى به

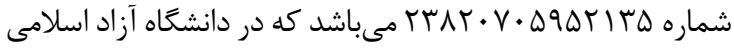

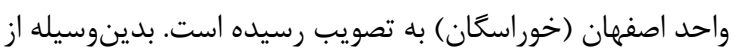
شركت كنند

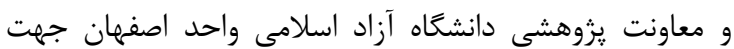
همكارى و حمايت مالى از اين طرح قدردانى مىشود. همجنين،

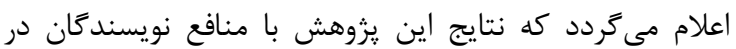
تعارض نمى باشد.

\section{REFERENCES}

1. American Psychiatric Association. Diagnostic and statistical manual of mental disorders (DSM-5). $5^{\text {th }}$ ed. Trans: Rezaee F, Fakhraee A, Farmand A, Niloufari A, Hashemi J, Shamloo AF. Tehran: Arjmand; 2013. P. 101-4. [Persian]

2. Sadock B, Ruiz P. Kaplan \& Sadoks synapsis of psychiatry: behavioral science. Trans: Rezaei F. $11^{\text {th }}$ ed. Tehran: Arjmand; 2016. P. 447. [Persian]

3. Monestra VJ, Lynn S, Linden M, Lubar JF, Gruzelier J, VaqueTJ. Elctroencephalographic biofeedback in the treatment of attention-deficit/hyperactivity disorder. $J$ Neurother. 2006;9(4):5-34. DOI: 10.1300/J184v09n04_02

4. Tinus TP. The integrated visual and auditory continuous performance test as a neuropsychological measure. Arch Clin Neuropsychol. 2003;18(5):439-54. PMID: 14591441

5. Moreno-García I, Delgado-Pardo G, Camacho-Vara de Rey C, Meneres-Sancho S, Servera-Barceló M. Neurofeedback, pharmacological treatment and behavioral therapy in hyperactivity: multilevel analysis of treatment effects on electroencephalography. Int $J$ Clin Health Psychol. 2015;15(3):217-25. PMID: 30487839 DOI: 10.1016/j. ijchp.2015.04.003

6. Lerner JW. Children with learning disabilities: theories, diagnosis teaching strategies. $2^{\text {nd }}$ ed. Trans: Rakhshan F, Feryar A. Tehran: Mabna; 2014. P. 199. [Persian]

7. Moreno-García I, Delgado-Pardo G, Roldán-Blasco C. Attention and response control in ADHD. Evaluation through
عدم معنادارى نتايج شده باشد. از ديخر مواردى كه در ارتباط با

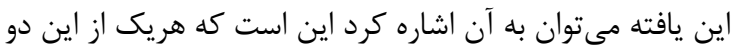

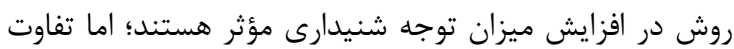

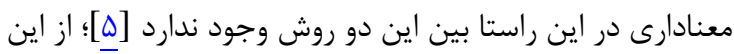

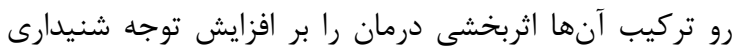

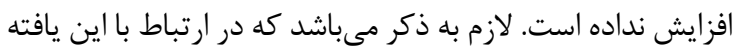

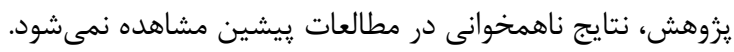

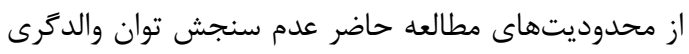
والدين قبل از آموزش والدگرى بود كه در اين زمينه مهاينه توصيه

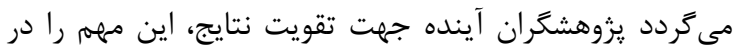

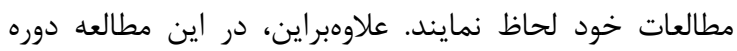

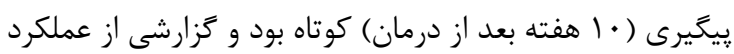

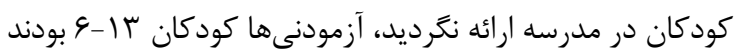

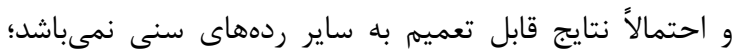

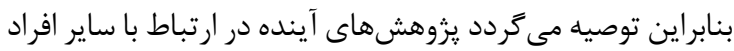
ADHD

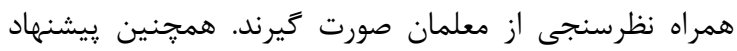

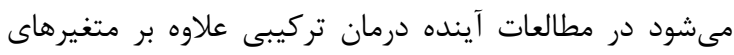

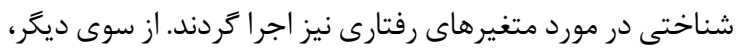

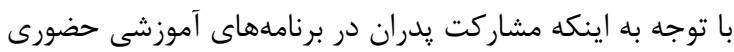

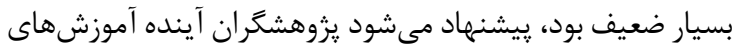

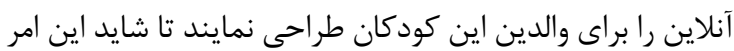
مشاركت هر دو والد در برنامه درمان را تسهيل كند.

\section{نتيجه تيرى}

اگرجه هر دو روش درمانى نوروفيدبك و نوروفيدبك به

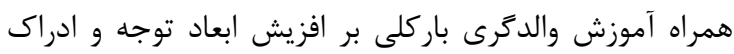

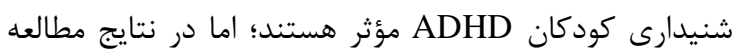

integrated visual and auditory continuous performance test. Span J Psychol. 2015;18(1):1-14. PMID: 25734571 DOI: 10.1017/SJP.2015.2

8. Safer DJ, Zito JM, Fine EM. Increased methylphenidate usage for attention deficit disorder in the 1990s. Pediatrics. 1996;98(6):1084-92.

9. Smith BH, Barkley RA, Shapiro CJ. Attention-deficit/ hyperactivity disorder. In: Mach EJ, Barkley RA, editors. Treatment of childhood disorders. New York: Guilford; 2006. P. 65-136.

10. Nazari MN, Querne L, De Broca A, Berquin P. Effectiveness of EEG biofeedback as compared with methylphenidate in the treatment of attention-deficit/ hyperactivity disorder: Clinical Outcome Study. Neurosci Med. 2011;2(2):78-86.

11. Arns M, De Ridder S, Strehl U, Breteler M, Coenen A. Efficacy of neurofeedback treatment in ADHD: the effects on inattention impulsivity and hyperactivity: a meta-analysis. Clin EEG Neurosci. 2009;40(3):180-9. DOI: 10.1177/ 155005940904000311

12. Vernon D. Can neurofeedback training enhance performance? An evaluation of the evidence with implications for future research. Appl Psychophysiol Biofeedback. 2005;30(4):34764. PMID: 16385423 DOI: $10.1007 / \mathrm{s} 10484-005-8421-4$

13. Schneiders JA, Opitz B, Krick CM, Mecklinger A. Separating intra-modal and across-modal training effects in visual working memory: an fMRI investigation. Cereb 
Cortex. 2011;21(11):2555-64. PMID: 21471559 DOI: 10.1093/cercor/bhr037

14. Norizade N, Mikaeli MF, Rostami R, Sadeghi V. The effectiveness of neurofeedback training on comorbid LD and ADHD. J Learn Disabilt. 2012;2(2):123-58. [Persian]

15. Heath CL, Curtis DF, Fan W, McPerson R. The association between parenting stress, parenting self-efficacy, and the clinical significance of child ADHD symptom change following behavior therapy. Child Psychiatry Hum Dev. 2015;46(1):118-29. PMID: 24668566 DOI: 10.1007/s10578014-0458-2

16. Behbahani M, Zargar F. Effectiveness of mindful parenting training on clinical symptoms and self-efficacy in children with attention deficit hyperactivity disorder. J Isfahan Med Sch. 2017;35(429):511-7. [Persian]

17. Barkley RA. Taking charge of ADHD: The complete authoritative guide for parents. $3^{\text {rd }}$ ed. Trans: Abedi A, Sharbafzadeh A. Esfahan: Kavoshyar; 2015. P. 268. [Persian]

18. Arble E, Kuentzel J, Barnett D. Convergent validity of the integrated visual and auditory continuous performance test(IVA+Plus): associations with working memory, processing speed, and behavioral ratings. Arch Clin Neuropsychol. 2014;29(3):300-12. PMID: 24687587 DOI: 10.1093/arclin/acu006

19. Strauss E, Sherman EM, Spreen O. A compendium of neuropsychological tests: administration, norms, and commentary. $3^{\text {rd }}$ ed. New York: American Chemical Society; 2006.

20. Madani AS, Heidarinasab L, Yaghubi H, Rostami R. Surveying effectiveness of neuro-feedback in reduction of attention and concentration deficit symptoms in ADHD adults. Clin Psychol Personal. 2015;2(11):85-98. [Persian]

21. Bakhshi S. Effect of selected attention-related tasks on sustained attention in children with attention deficit hyperactivity disorder. [BSc Thesis]. Tehran: University of Social Welfare and Rehabilitation Sciences; 2010. [Persian]

22. Hillard B, El-Baz AS, Sears L, Tasman A, Sokhadze EM. Neurofeedback training aimed to improve focused attention and alertness in children with ADHD: a study of relative power of EEG rhythms using custommade software application. Clin EEG Neurosci. 2013;44(3):193-202. PMID: 23820311 DOI: $10.1177 / 1550059412458262$

23. Hosseini MH, Pritchard-Berman M, Sosa N, Ceja AA, Kesler SR. Task-based neurofeedback training: a novel approach toward training executive functions. Neuroimage. 2016; 134:153-9. PMID: 27015711 DOI: 10.1016/j.neuroimage. 2016.03.035

24. Sayala S, Sala JB, Courtney SM. Increased neural efficiency with repeated performance of a working memory task is information-type dependent. Cereb Cortex. 2006;16(5):60917. PMID: 16079245 DOI: $10.1093 /$ cercor/bhj007

25. Haller S, Kopel R, Jhooti P, Haas T, Scharnowski F, Lovblad $\mathrm{KO}$, et al. Dynamic recon figuration of human brain functional networks through neurofeedback. Neuro Image. 2013;81:243-52. PMID: 23684872 DOI: 10.1016/j. neuroimage.2013.05.019

26. Arns M, Conners CK, Kraemer HC. A decade of EEG theta/beta ratio research in ADHD: a meta-analysis. $J$ Atten Disord. 2013;17(5):374-82. PMID: 23086616 DOI: 10.1177/1087054712460087

27. Ogrim G, Hestad KA. Effects of neurofeedback versus stimulant medication in attention-deficit/hyperactivity disorder: a randomized pilot study. J Child Adolesc Psychopharmacol. 2013;23(7):448-57. PMID: 23808786 DOI: 10.1089/cap.2012.0090

28. Holtmann M, Stadler C. Electroencephalographic biofeedback for the treatment of attention-deficit hyperactivity disorder in childhood and adolescence. Expert Rev Neurother. 2006;6(4):533-40. PMID: 16623652 DOI: 10.1586/14737175.6.4.533

29. Kordestani D, Radmanesh H, Salary M, Amiri M, Farhood F. Investigating the efficacy of training behavior modification strategies to parents of ADHDs on parenting stress reduction and behavior improvement in children. Behav Sci J. 2013;7(3):263-9. [Persian]

30. Abedy AR, Seyyedghaleh A, Bahramipour M. Comparison of the effectiveness of filial therapy and Barkley's parent training program in reducing the symptoms of anxiety and ADHD in children. Excep Child. 2017;17(3):111-20. [Persian]

31. Egner T, Gruzelier JH. Learned self-regulation of EEG frequency components affects attention and event-related brain potentials in humans. Neuroreport. 2001;12(18):41559. PMID: 11742256

32. Schonenberg M, Wiedemann E, Schneidt A, Scheeff J, Logemann A, Keune PM, et al. Neurofeedback, sham neurofeedback, and cognitive-behavioral group therapy in adults with attention-deficit hyperactivity disorder: a tripleblind, randomized, controlled trial. Lancet Psychiatry. 2017;4(9):673-84. DOI: 10.1016/S2215-0366(17)30291-2

33. Hodgson K, Hutchinson AD, Denson L. Nonpharmacological treatments for ADHD: a meta-analytic review. $J$ Atten Disord. 2014;18(4):275-82. PMID: 22647288 DOI: 10.1177/1087054712444732

34. Chacko A, Uderman JZ, Zwilling A. Lessons learned in enhancing behavioral parent training for high-risk families of youth with ADHD. ADHD Rep. 2013;21(4):6-11. PMID: 25541576 DOI: 10.1521/adhd.2013.21.4.6 